\title{
Neuronal synchronization and multiscale information processing
}

\author{
Meyer Pesenson \\ From Twenty First Annual Computational Neuroscience Meeting: CNS*2012 \\ Decatur, GA, USA. 21-26 July 2012
}

\begin{abstract}
Many important processes in neurobiology as well as neuronal engineering applications rely upon multiresolution representation and analysis of external information. There are various approaches which attempt to explain how human perception systems perform multiscale representation and sparse coding. The model proposed here is based on a new approach to multiresolution of input signals and reveals synchronization as a general mechanism for multiscale representation common to various sensory systems. The proposed mechanism is nonlinear and adaptive in the sense that it does not rely on convolution with a preconceived basis. For the visual system this approach is a major departure from the current linear paradigm, which holds that the structure of the receptive fields and their variations are responsible for performing multiscale analysis. While there are some well-known, important roles played by entrainment in neuronal systems, our model reveals a new function of dynamic coordination in the brain - multiscale encoding, thus demonstrating that synchronization plays a greater role in perception in general and in vision in particular, than was previously thought.
\end{abstract}

\section{Acknowledgements}

This work was supported by the grant from NGA, NURI HM1582-08-1-0019, and the grant AFOSR, MURI Award FA9550-09-1-0643.

Published: 16 July 2012

doi:10.1186/1471-2202-13-S1-014

Cite this article as: Pesenson: Neuronal synchronization and multiscale

information processing. BMC Neuroscience 2012 13(Suppl 1):O14.

Correspondence: mzp@cms.caltech.edu

Computing and Mathematical Sciences Department, Caltech, Pasadena, CA 91125, USA

(c) 2012 Pesenson; licensee BioMed Central Ltd. This is an Open Access article distributed under the terms of the Creative Commons

Submit your next manuscript to BioMed Central and take full advantage of:

- Convenient online submission

- Thorough peer review

- No space constraints or color figure charges

- Immediate publication on acceptance

- Inclusion in PubMed, CAS, Scopus and Google Scholar

- Research which is freely available for redistribution 